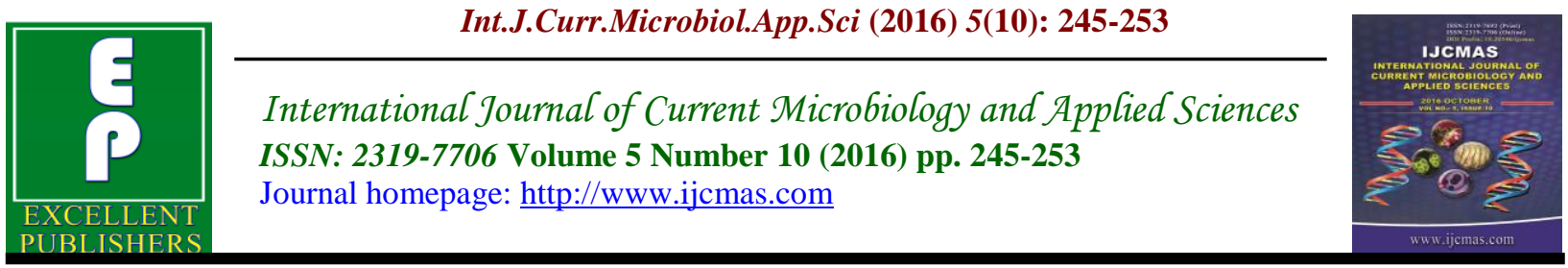

Original Research Article

http://dx.doi.org/10.20546/ijcmas.2016.510.027

\title{
Characterization of Biofilm forming Bacteria (Pseudomonas aeruginosa) UTI Infection
}

\author{
Kirti Kushwaha*, Abhishek Gupta, Dharmendra Singh and Arpita Shrivastav \\ Center for Microbiology and Biotechnology (CMBT) Research and training institute, \\ Bhopal (M.P.) India \\ *Corresponding author
}

Keywords

Pseudomonas aeruginosa, UTI Infection, Biofilm forming Bacteria.

\section{Article Info}

Accepted:

12 September 2016

Available Online:

10 October 2016

\section{A B S T R A C T}

A biofilm is an assemblage of microbial cells that is irreversibly associated with a surface and enclosed in a matrix of primarily polysaccharide material. A biofilm is an intricate aggregation of microorganisms growing on a solid substrate. It acts as a defensive tool for microorganisms during various stress conditions. The proposed work was carried out to study the biofilm forming ability of microorganisms specifically Pseudomonas aeruginosa five UTI samples different unwell age group persons from Shagun Pathology Lab. The bacteria were isolated from using King's media which is selective for growth of Pseudomonas Morphological and biochemical characterizations of isolates were carried out. All five isolates were found to be Gram negative chains resembling like Pseudomonas aeruginosa. Biochemical identification was performed. Citrate test was negative for all the isolates. Sugar fermentation using different sugars like Mannitol, lactose, dextrose, maltose and sucrose indicated only acid production, Urease test is positive from all samples. Biofilm forming ability was studied by cover slip essay, dry weight easy, Congo red agar method (CRA), Tube assay (Ring formation in glass surface); Cell surface Hydrophobicity and Effect of carbon source utilization. Different antibiofilm agents will be further screened for the anti-Biofilm potential.

\section{Introduction}

\section{UTI Infection}

UTI is one of the most common bacterial infections in women of all ages and the incidence and prevalence increase with age. More than half of all women have at least one UTI in their lifetime and the risk of contracting a UTI increases in postmenopausal women. Among healthy no institutionalized old women UTI is the most common infection and in residents of long - term care facilities UTI is even more common. UTI is more common among old women because of a variety of anatomic and functional changes which arise with aging, such as hormonal changes, reduced uromucoid secretions, decreased renal ability and increased bacterial adherence to uroepithelial cells. Hormonal changes, such as decreased estrogen may contribute to increased UTI prevalence in older women. Reduced uromucoid secretions may contribute to a decreased Antibacterial 
activity and reduced renal ability to excrete acid and urea; this in turn may increase the bacterial colonization of the bladder. Several other factors contribute to the high occurrence of UTI among the old, Such as incomplete bladder emptying, previous stroke, the presence of an indwelling urinary catheter (IUC) and a history of UTI at younger ages.

\section{Biofilm}

Formation of a biofilm begins with the connection of free-floating microorganisms to an outside. These initial colonists stick to the surface initially during scrawny, reversible van der Waals forces. If the colonists are not right away divided on or after the outside, they are able to secure themselves extra enduringly with cell adhesion structures such like pili (LappinScott et al., 2003).

The first colonists make possible the entrance of additional cells by given that more various adhesion sites and creation to assemble the atmosphere that holds the biofilm mutually. a quantity of species are not capable to fix to a surface on their individual but are frequently capable to attach themselves to the matrix or straight to previous colonists.

It is during this colonization that the cells are able to correspond by quorum sensing using such products as AHL. Once colonization has begin, the biofilm grows through a grouping of cell division and staffing. The concluding stage of biofilm arrangement is known as development, and is the stage in which the biofilm is recognized and can only modify in shape and size. The growth of a biofilm may permit for the combined cell colony to be increased antibiotic resistant (Stewart, et al., 2001).

\section{Characteristics of Biofilm}

Distinctiveness of biofilms with the intention of preserve be there essential in infectious infection processes comprise.

Disengagement of cells or biofilm aggregates can cause in bloodstream or urinary tract infections or in the construction of emboli,

Cells may replace confrontation plasmids inside biofilms, Cells in biofilms comprise spectacularly compact receptiveness to antimicrobial agents.

Antoine Van Leeuwenhoek, using his simple microscopes, first experiential microbes on tooth surfaces and can survive accredited with the innovation of microbial Biofilm. Heukelekian and Heller experiential the "bottle effect" for aquatic microorganisms, i.e., bacterial growth and action be significantly superior next to the integration of a surface to which these organisms could attach (Heukelekian et al., 1940). Pragmatic that the amount of bacteria on surfaces was significantly higher than in the immediate medium (in this case, seawater) (Zobell et al., 1943). Microbial slimes during industrial water systems and showed that they were not only very tenacious except also highly opposing to disinfectants such like chlorine. Based on explanation of dental plaque and sessile communities in mountain streams (Characklis et al., 1973).

Theory of biofilms that explained the mechanisms whereby microorganisms adhere to living and nonliving equipment and the reimbursement accrued by this ecologic niche (Costerton et al., 1978). Much of the work in the last 2 decades has relied on tools such as scanning electron microscopy (SEM) or standard microbiologic culture techniques for biofilm characterization. 


\section{Materials and Methods}

\section{Isolation of Pseudomonas UTI Samples}

UTI sample were collected from Shagun Pathology Bhopal and inoculated in King's agar medium and was incubated at $37^{\circ} \mathrm{C}$ for 24 hours. Colony characteristics of randomly isolated colonies were recorded. Gram staining was performed.

\section{Biochemical characterization}

Selected colonies were further characterized for various biochemical tests including Amylase production test, Urease test, Catalase activity, Sugar fermentation test, Methyl red test, Cellulase production test, Iodole production test, Microbial reactions in litmus test, Casein hydrolysis test, Hydrolysis of gelatin, a protein (production of gelatinase) test (Aneja, 2003).

\section{Screening of isolates for Biofilm formation}

\section{Congo-Red Assay}

Biofilm formation by the isolates was checked by using Congo red agar (CRA) medium (Freeman et al., 1989). Sterile CRA plates were inoculated and incubated at 37 ${ }^{0} \mathrm{C}$ for 24 hours. Black colonies with dry crystalline consistency were considered to be positive for biofilm production.

\section{Tube Assay}

Preparation of LB medium whose constitute per liter $10 \mathrm{gm}$ trypton, $5 \mathrm{gm}$ yeast extract, $10 \mathrm{gm} \mathrm{NaCl}$. Dissolve LB broth media in 20 $\mathrm{ml}$ of water. Sterilized it by autoclaving at $121^{\circ} \mathrm{C}$ for $15 \mathrm{~min}$. pour the autoclaved medium in voiles and closed it. Inoculate pseudomonas to the help of inoculation loop. Incubate inoculated voiles with pseudomonas at $37^{\circ} \mathrm{C}$ for $3-5$ days in Observe the voiles for the formation of ring in the voiles.

\section{Cell surface hydrophobicity}

Cell surface hydrophobicity was determined by microbial adhesion to hydrocarbon (MATH) as described originally by Rosenberg et al, with modification, briefly bacteria were grown in TSB at $37^{\circ} \mathrm{C}$ for 18 to $24 \mathrm{Hr}$, harvested by centrifugation (5000rpm, $10 \mathrm{~min}, 25^{\circ} \mathrm{C}$ ) washed with and resuspended in sterile distill water to an initial A 600 of 0.3 to 0.6 and measured using digital photocolory meter (model 312, EI) at wavelength of $620 \mathrm{~nm}\left(\mathrm{OD}_{620} \mathrm{~nm}\right)$. Two $\mathrm{ml}$ each of the adjusted bacterial suspension and xylene were mixed for $2 \mathrm{~min}$ by vortex in borosilicate glass tube at room temperature. The phase was allowed to separate for $1 \mathrm{~h}$ at ambient temperature, and A 600 of lower aqueous phase was measured as before. Cell surface hydrophobicity was calculated from ( $\mathrm{A}_{\text {initial }}{ }^{-}$ A aqueous $/ A$ initial $x$ 100). Triplicate determination was made for each for each of 2 separate cultures of all the isolate. We used xylene as the hydrocarbon phase because it is more hydrophobic and can permit the detection of relatively less hydrophobic cell than aliphatic hydrocarbon such as hexadecane.

\section{Development of biofilm on cover slip assay}

With some modification we developed protocol for biofilm formation and characterization on cover slip and glass slide. For this purpose we used compound microscope (replaced with electron microscope) for the development of biofilm on glass slide of culture were inoculated into LB agar and incubated at $37^{\circ} \mathrm{C}$ for 24 hours. Then cultures were wash with sterilized 
water and dried at room temperature (R.T.). Stained with crystal violet for 20 minutes, wash with distill water and dried and then wash with Distilled water and observed under microscope for biofilm formation.

\section{Exopolysaccharide assay}

Exopolysaccharide produced by each of the isolates was extracted with modification. Bacteria were grown in TSB broth $\left(37^{\circ} \mathrm{C}\right.$, 24h) with shaking and cell harvested By centrifugation $(6000 \mathrm{rpm} \times 20 \mathrm{~min} \times \mathrm{RT})$ the cell were washed with $1 \mathrm{M} \mathrm{NaCl}-10 \mathrm{~mm}$ Ethylene diamine tetra-acetic acid (EDTA) solution to release cell-bound EPS, and supernatant was added to culture supernatant, which contained soluble EPS.

The supernatant mixtures were extracted with 2 volume of cold $\left(-20^{\circ} \mathrm{C}\right)$ ethanol for at least for $12 \mathrm{~h}$ at $4^{\circ} \mathrm{C}$ to precipitate EPS, which was collected by Centrifugation (6000rpm $\times 20 \mathrm{~min} \times 4 \quad{ }^{\circ} \mathrm{C}$ ). $\quad$ Protein contaminants in the EPS were precipitated with $20 \%$ Trichloroacetic acid on ice for at least $45 \mathrm{~min}$ and removed by centrifugation. EPS in the resulting filtrates was then reprecipitated with 2 volumes of cold ethanol and air dried. The carbohydrate content of EPS was assayed by the device method using D-glucose as standard. The experiment was done total of 3 times.

\section{Effect of different carbon source in biofilm formation}

Bacteria were grown in media containing LB-broth, LB-Maltose, LB-Lactose, LBSucrose, LB-Manitol, and LB-Dextrose. Biofilm formed in microfuge tube was quantified by using digital colorimeter at OD $620 \mathrm{~nm}$. Results are mean of a single representative triplicate determination using 4 independent samples.

\section{Determination of biofilm dry weight}

With some modification in the protocol of dry weight of biofilm we determined the dry weight of biofilm. Incubate bacterial culture in polypropylene microfuge tube with LB broth and incubate at $37{ }^{\circ} \mathrm{C}$ for $24 \mathrm{hrs}$. After incubation wash biofilm with distill water and stained by methyl in blue and measured dry weight of biofilm.

\section{Result and Discussion}

\section{Microbial analysis}

Five samples of pseudomonas different age group of humans (20-85) were collected from Shagun Pathology Lab of Bhopal. The samples were isolated from UTI sample. All the samples were spread on King'S agar media plates and kept overnight at $37{ }^{\circ} \mathrm{C}$.

\section{Growth on selective media}

The selective media are those, which permit the growth of some of specific group of organisms while preventing or retarding the growth of other, thus facilitating bacterial isolation. The selective action is brought by the addition of certain chemicals in the medium e.g., the dye crystal violet is selectively bacteriostatic for gram-positive bacteria and favors enteric pathogens (Plaza and Munoz, 2001).

The differential media were used to identify some pseudomonas. That was King's agar medium. All selected 5 isolated cultures were poured on the above mentioned media. Out of which only five culture tagging i.e., S-1, S-2, S-3, S-4 and S-5 was showed their growth on media.

\section{Effect of carbon source on bacterial formation}

All strain of Pseudomonas aeruginosa is exposed to different sources of carbon that 
may differ from the sources available in the host, we examined whether exposure to a number of sources of carbon would have an effect on the establishment of a Biofilm.

Table.1 Name of Micro-organism with sample ID:

\begin{tabular}{|c|c|c|c|c|c|c|}
\hline S.No. & Name & Gender & Disease & $\begin{array}{c}\text { Name of } \\
\text { Microorganism }\end{array}$ & $\begin{array}{c}\text { Age } \\
\text { group }\end{array}$ & $\begin{array}{c}\text { SAMPLE } \\
\text { ID }\end{array}$ \\
\hline 1. & $\begin{array}{c}\text { Prayagraj } \\
\text { Soni }\end{array}$ & Male & UTI & $\begin{array}{c}\text { Pseudomonas } \\
\text { aeruginosa }\end{array}$ & 29 & S-1 \\
\hline 2. & $\begin{array}{c}\text { Santosh } \\
\text { Lata }\end{array}$ & Female & UTI & $\begin{array}{c}\text { Pseudomonas } \\
\text { aeruginosa }\end{array}$ & 79 & S-2 \\
\hline 3. & N. Sharma & Male & UTI & $\begin{array}{c}\text { Pseudomonas } \\
\text { aeruginosa }\end{array}$ & 85 & S-3 \\
\hline 4. & $\begin{array}{c}\text { Sunita } \\
\text { Yadav }\end{array}$ & Female & UTI & $\begin{array}{c}\text { Pseudomonas } \\
\text { aeruginosa }\end{array}$ & 25 & S-4 \\
\hline 5. & Deepak & Male & UTI & $\begin{array}{c}\text { Pseudomonas } \\
\text { aeruginosa }\end{array}$ & 20 & S-5 \\
\hline
\end{tabular}

Table.2 Effect of carbon source on biofilm formation

\begin{tabular}{|c|c|c|c|c|c|}
\hline Carbon Sources & Dextrose & Sucrose & Maltose & Mannitol & Lactose \\
\hline S-1 & 1.733 & 1.603 & 1.019 & 1.842 & 1.347 \\
\hline S-2 & 1.723 & 1.790 & 1.514 & 1.642 & 1.632 \\
\hline S-3 & 1.674 & 1.820 & 1.675 & 1.733 & 1.758 \\
\hline S-4 & 1.885 & 1.771 & 1.520 & 1.726 & 1.354 \\
\hline S-5 & 1.068 & 1.610 & 1.656 & 1.751 & 1.542 \\
\hline
\end{tabular}

Table.3 Exopolysaccharide (EPS) yield of selected micro-organism in $\mathrm{mg} / \mathrm{ml}$

\begin{tabular}{|c|c|c|}
\hline S.no & Bacterial Strain & Absorbance (Dextrose) \\
\hline 1 & S-1 & $\mathbf{9 9 . 3 1 5}$ \\
\hline 2 & S-2 & $\mathbf{1 0 0 . 4 0 3}$ \\
\hline 3 & S-3 & 106.025 \\
\hline 4 & S-4 & 1.88 \\
\hline 5 & S-5 & 1.145 \\
\hline
\end{tabular}


Table.4 Scavenging activity of Pseudomonas aeruginosa on CSH

\begin{tabular}{|c|c|c|}
\hline S.NO. & Bacterial strain & CHS \\
\hline 1 & S-1 & 51.887 \\
\hline 2 & S-2 & 27.740 \\
\hline 3 & S-3 & 7.600 \\
\hline 4 & S-4 & 0.758 \\
\hline 5 & S-5 & 28.400 \\
\hline
\end{tabular}

Graph.1 The graph showing dry weight of Biofilm formed by oral isolates on polypropylene surface

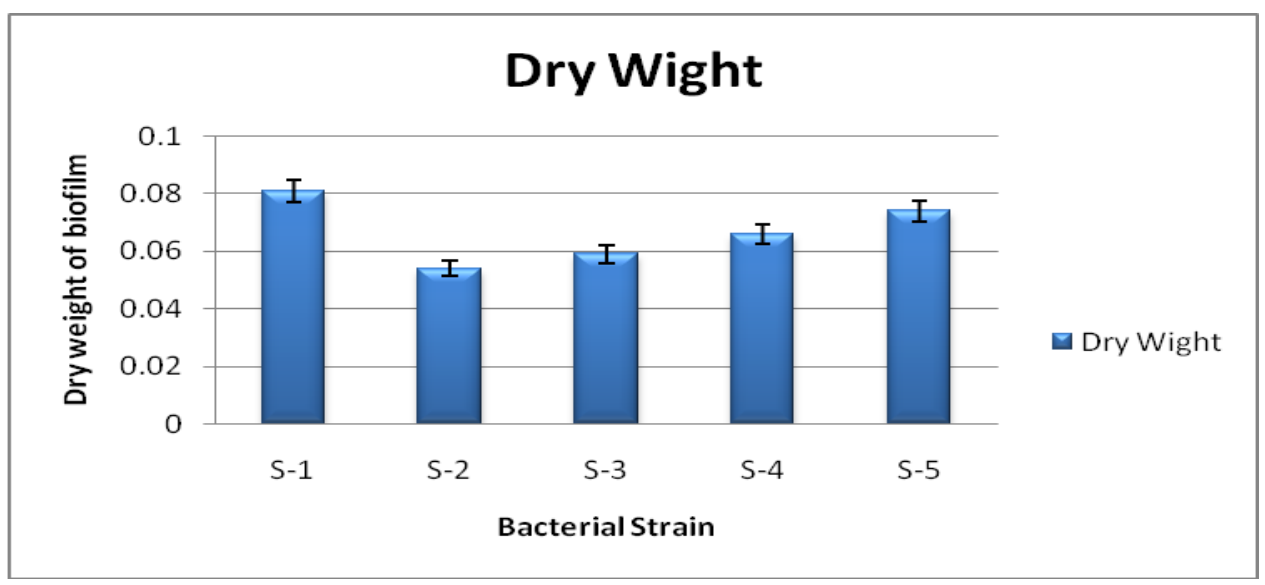

Graph.2 The graph showing bacterial growth of Biofilm in formed by bacterial isolates with different carbon sources

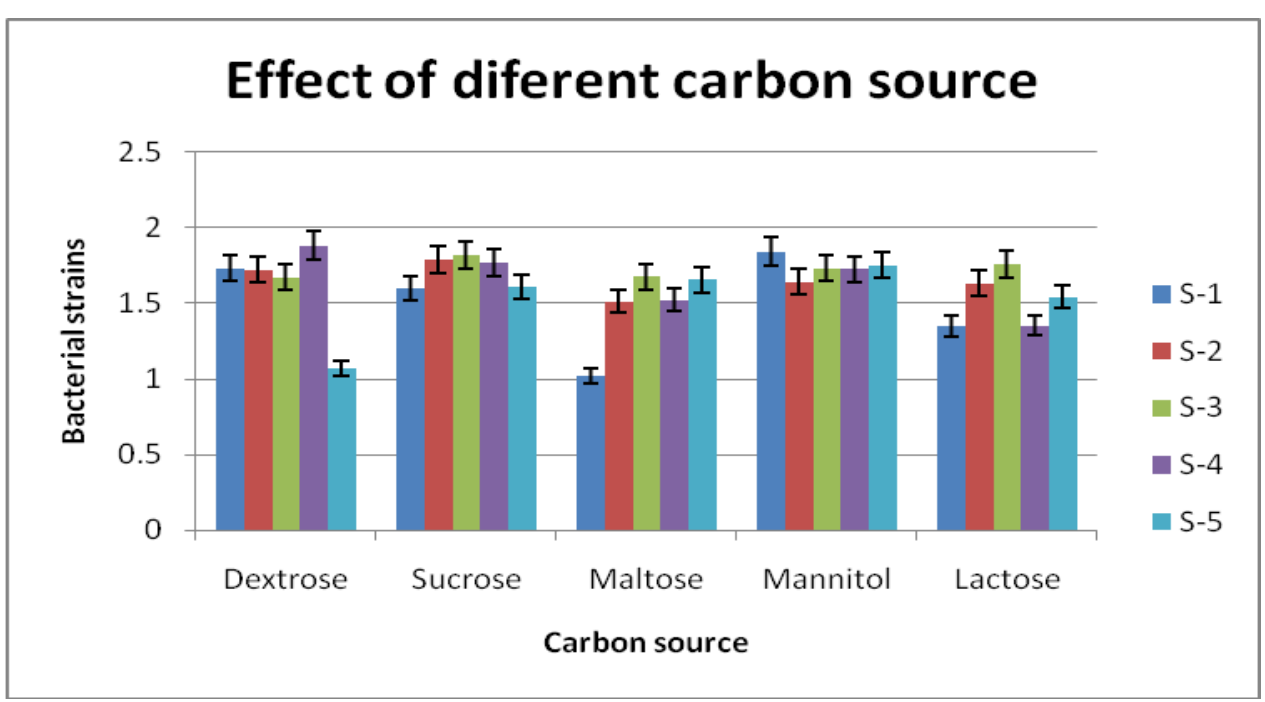


Graph.3 Standard curve of dextrose

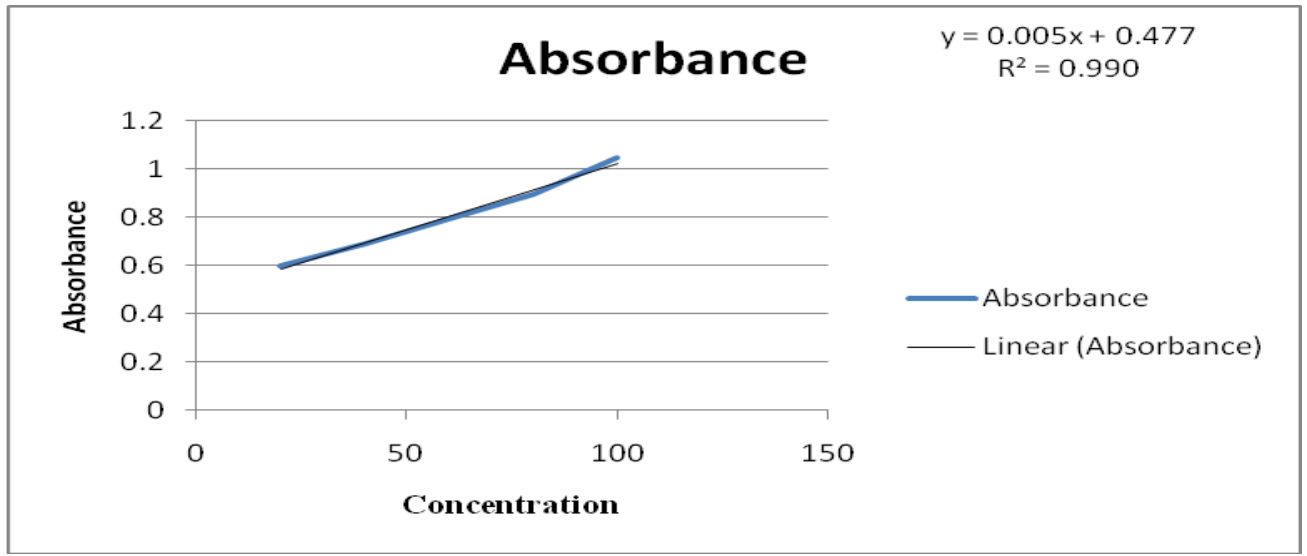

Graph.4 The showing bacterial exopolysaccharide produced by Pseudomonas aeruginosa with Dextrose carbon source.

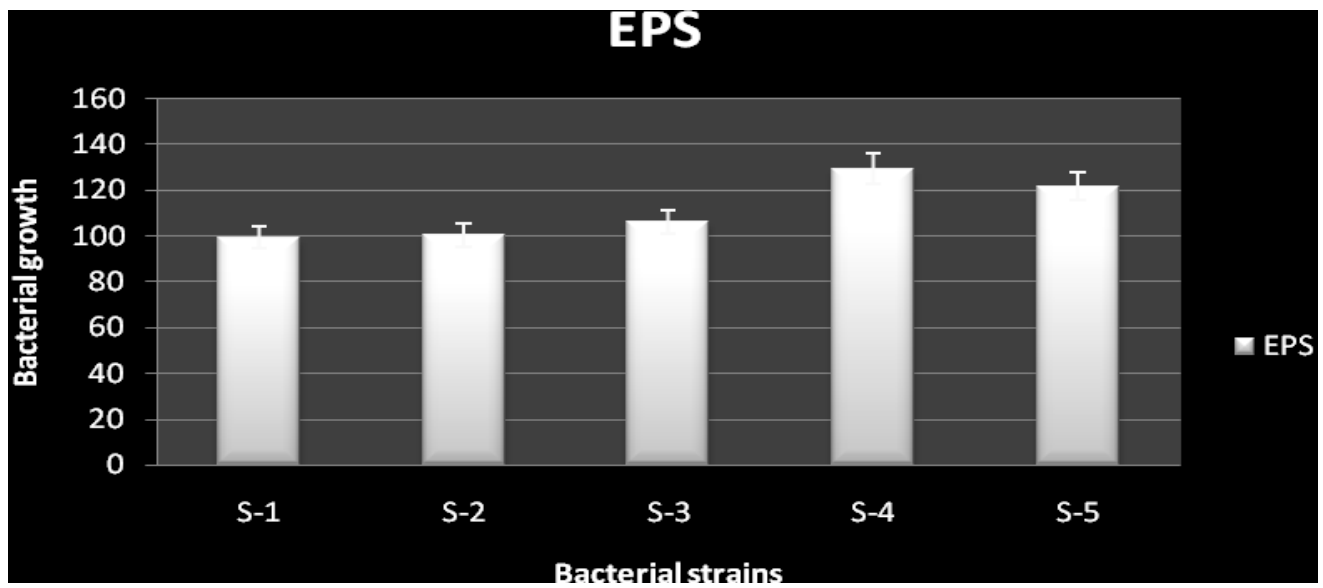

Graph.5 The graph showing bacterial cell surface hydrophobicity produced by Pseudomonas aeruginosa with scavenging.

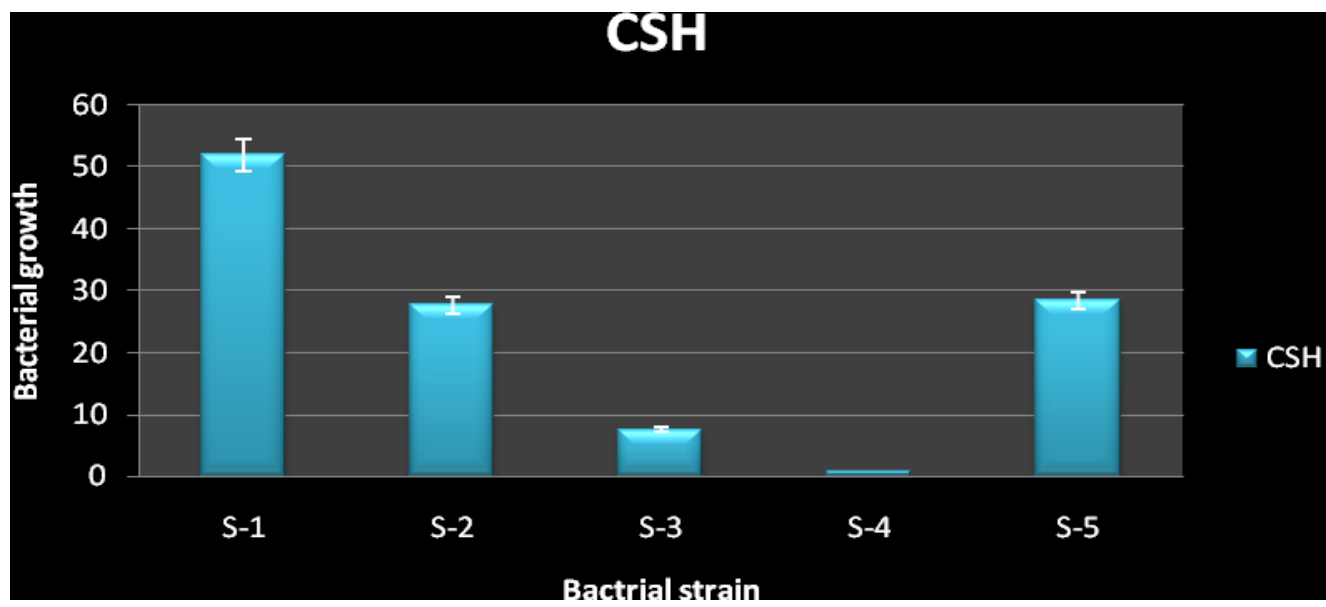


Fig 1 formation of Biofilm on Congo red agar medium (CONGO RED ASSAY)

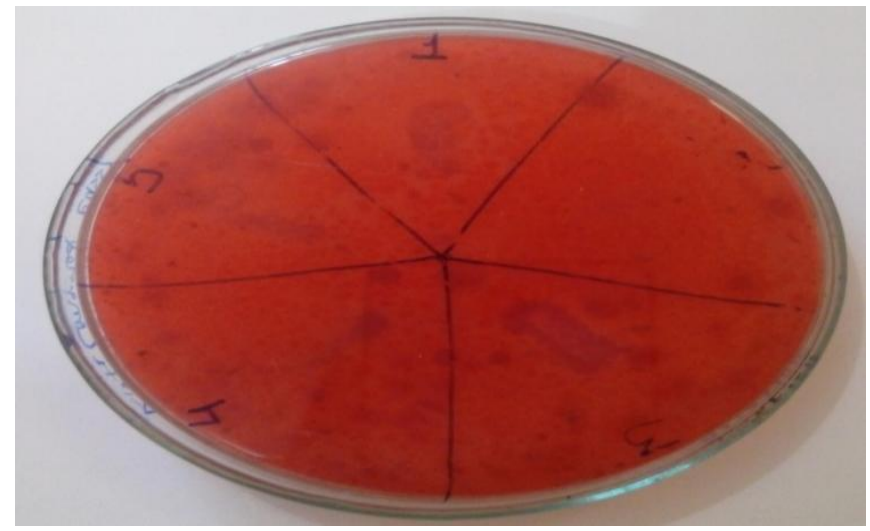

Fig 2 Ring formation by Pseudomonas aeruginosa TUBE ASSAY (RING FORMATION)

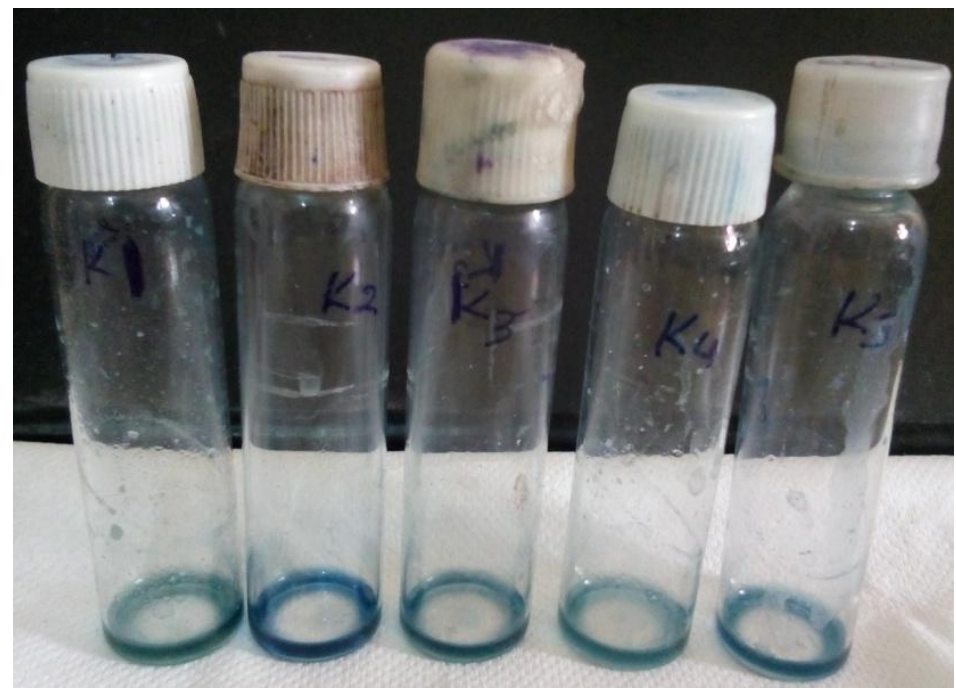

Fig 3 Microscopic analysis by Cover slip assay:

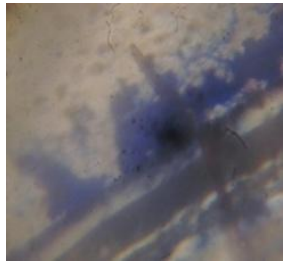

Fig: 1

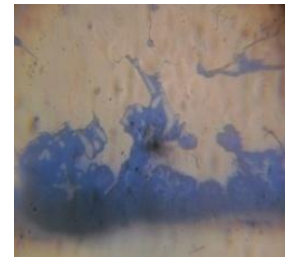

Fig: 2

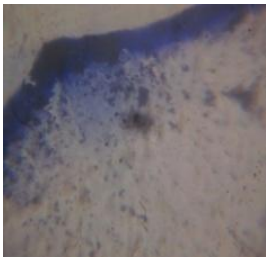

Fig: 3

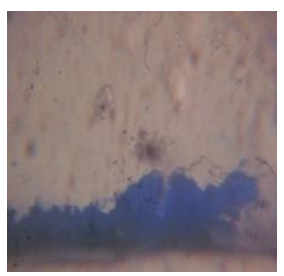

Fig: 4

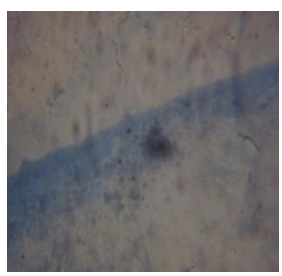

Fig: 5
In conclusion, the stable expression of microbial communication by Pseudomonas provides a useful method for studying the interaction(s) of this pathogen in Biofilm. The utilization of carbon in combination with the pseudomonas EPS-expressing will make it possible to visualize bacterial behavior in homogeneous and mixed-species approach should
Biofilm. This accelerate the 
characterization of the pseudomonas as a virulence factor and contribute to our understanding of how pseudomonas behaves in Biofilm such as UTI Infections.

The Biofilm forming bacteria formed biofilm on PP surface, show surface adheretion and its having pathogenic nature and cause various type of diseases, the result of the study also supports the know about carbon utilization by different isolates of Pseudomonas aeruginosa and formation of biofilm by production of exopolysaccharide and surface adheretion are the further challenges.

\section{References}

Characklis, W.G., McFeters, G.A., Marshall, K.C. 1978. Physiological ecology in biofilm systems. In: Characklis WG,
Marshall KC, editors 1990 Biofilms. New York: John Wiley \& Sons. (Freeman et al., 1989) Biofilm formation by the isolates was checked by using CRA medium.

Costerton, J.W., Geesey, G.G., Cheng, K.J. 1978. How bacteria stick, Sci. Am.

Heukelekian, H., Heller, J. 1940. A Relation between food concentration and surface for bacterial growth, J. Bacterial.

Lappin-Scott, Hilary. 2003. Microbial Biofilms. Cambridge: Cambridge University Press.

Stewart, P.S., Costerton, J.W., 2008. Antibiotic resistance of bacteria in biofilms, Lancet, 358.

Zobell, C.E. 1943. The effect of solid surfaces on bacterial activity, $J$. Bacterial.

\section{How to cite this article:}

Kirti Kushwaha, Abhishek Gupta, Dharmendra Singh and Arpita Shrivastav. 2016. Characterization of Biofilm forming Bacteria (Pseudomonas aeruginosa) UTI Infection. Int.J.Curr.Microbiol.App.Sci. 5(10): 245-253. doi: http://dx.doi.org/10.20546/ijcmas.2016.510.027 